\title{
Missed Diaphyseal Fracture Humerus in Neonate
}

\author{
Mahendra Gudhe ${ }^{1 *}$, Vandana Gudhe ${ }^{2}$, Sohael khan ${ }^{1}$ and Suverna Gupta ${ }^{3}$ \\ ${ }^{1}$ Assistant Professor, Department of Orthopaedic, Jawaharlal Nehru Medical College,Wardha, India \\ ${ }^{2}$ Assistant Professor, School of Epidemiology, Jawaharlal Nehru Medical College,Wardha, india \\ ${ }^{3}$ Senior Resident, Department of Orthopaedic, Jawaharlal Nehru Medical college, Wardha, India
}

Submission: May 20, 2018; Published: July 05, 2018

*Corresponding author: Mahendra Gudhe, Assistant Professor, Department of Orthopaedic, Jawaharlal Nehru Medical College,Wardha, India, Email: Dr.mahendragudhe@gmail.com

\begin{abstract}
Introduction: Birth trauma is less with the Lower segment caesarean section delivery as compare to normal vaginal delivery. Post LSCS humerus fracture is a rare entity in neonatology [1]. But in some difficult extractions even with expert care, injury may be sustained by the newborn. Such injuries may get missed or remain unnoticed by an obstetrician and pediatrician in early neonatal period. Here we are presenting a case series of 2 cases in a period of one month where obstractician and neonatologist missed diaphysis humerus fracture in neonate induced by birth trauma during Caesarean section.
\end{abstract}

Keywords: Birth injury, Caesarean section, neonatal period, diaphysis humerus fracture

\section{Introduction}

Birth trauma complicates $1.1 \%$ of Caesarean deliveries. Caesarean section is considered to be safer than vaginal delivery. However, in certain cases, injury may be sustained by the newborn as a result of difficult extraction and the mechanics of delivery. Humerus fracture due to the birth trauma, which is extremely rare, can occur during Caesarean section [2]. Here we are presenting a case series of 3 cases in a period of one month where obstractician and neonatologist missed diaphysis humerus fracture in neonate induced by birth trauma during Caesarean section.

\section{Case 1}

A 5 day old male baby was referred to orthopedic department with swelling over the left arm and was not moving his left arm. The baby was delivered at 39 weeks of gestation by LSCS to a 24 year primigravida mother. Indication for LSCS was Breech presentation. Baby cried immediately after birth and was weighing $2.6 \mathrm{~kg}$. Apgar score was $8 / 10$ at 1 st and \% minutes. Operating surgeon gave a history of energetic traction as it was a difficulty delivery. X-ray of left arm was obtained which suggestive of spiral fracture shaft of left humerus. Subsequently baby was managed with Chest to arm strapping for 3 weeks and sent home [3]. Baby was followed up in OPD after 3 weeks. On 3 weeks follow up, clinical sign of uniting fracture was evident (Figure 1).

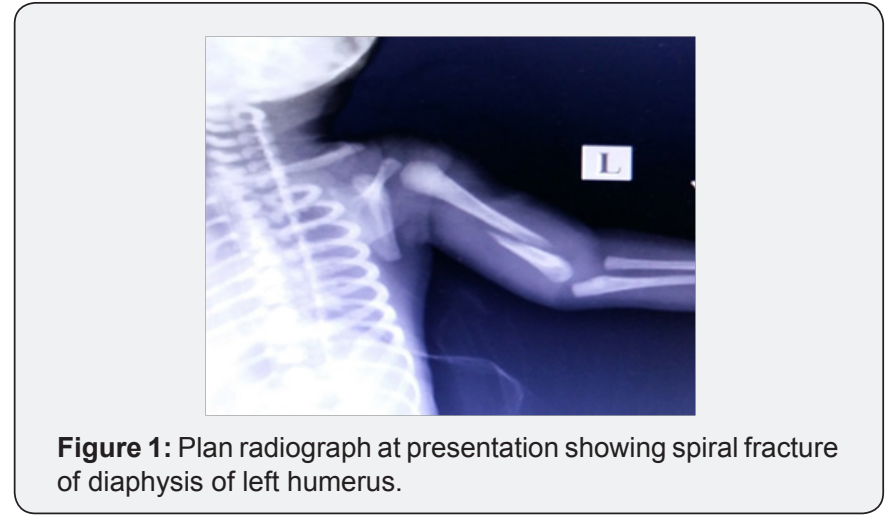

Case 2

A 7 days old female baby was referred to the orthopedic department with swelling over bilateral arm and was not moving her both arm. Baby was full-term newborn weighing $2.6 \mathrm{~kg}$ and was delivered by LSCS. The indication for the Lower segment caesarian section (LSCS) was short stature of mother, non-progression of labour and entanglement of cord around the neck. There was no history of consanguinity, metabolic bone disease, diabetes mellitus or syphilis in parents. When the baby was extracted, during a difficult Caesarean section, the obstetrician gave history of energetic traction and rotation during the section. The child cried immediately at birth, Apgar 
score was 8/10 at 1 and 5 minutes. Baby was shifted to ward. Mother noticed swellings of both the arms simultaneously and reduced activity of both upper limbs. On clinical examination, the swellings were tender with abnormal mobility was present. The rest of the general examination including skin was normal. The systemic examination also did not reveal any abnormalities. The radiograph of both Arms was done immediately showed bilateral humeral fractures. The newborn was immobilized with bilateral splints by the orthopedic consultant. The child improved and there was no residual deformity on discharge. No complications were noticed during the hospital stay (Figure 2).

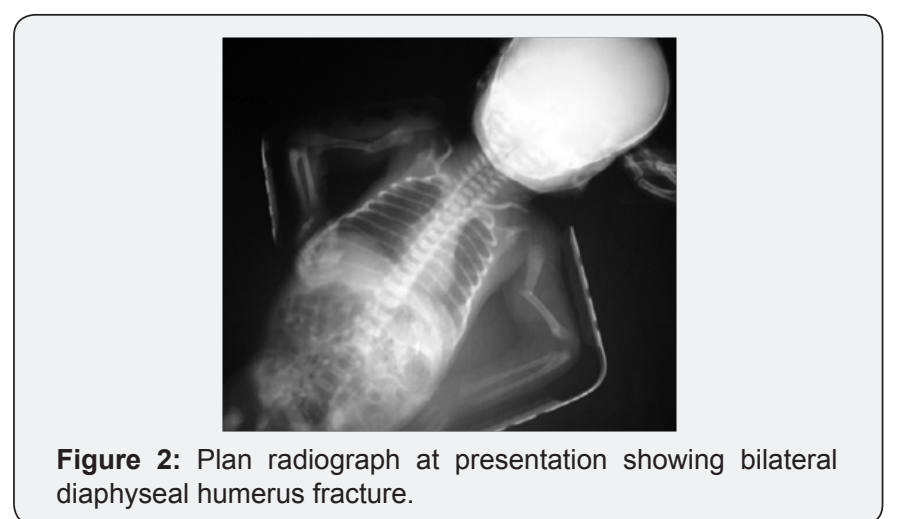

Case 3

A baby was delivered at 32 weeks of gestation by LSCS to a 30 year multi gravida mother. Indication for LSCS was Breech presentation with meconium aspiration. Baby didn't cried immediately after birth and was shift to NICU. Baby weight was $2.2 \mathrm{~kg}$. Apgar score was $4 / 10$ at $1 \mathrm{st}$ and 5 minutes. History of manual pressure and energetic traction was given by doctor as it was a difficulty delivery. Consulting doctor noticed swelling and reduced movement of left arm. Call was given to an Orthopedic Surgeon to examine the baby. On examination swelling was present over the left arm. X-ray of right arm was obtained, suggestive of spiral fracture shaft of lower 3rd humerus. Subsequently baby was managed with Chest to arm strapping for 3 weeks and sent home. Baby was followed up in OPD after 3 weeks (Figure 3).

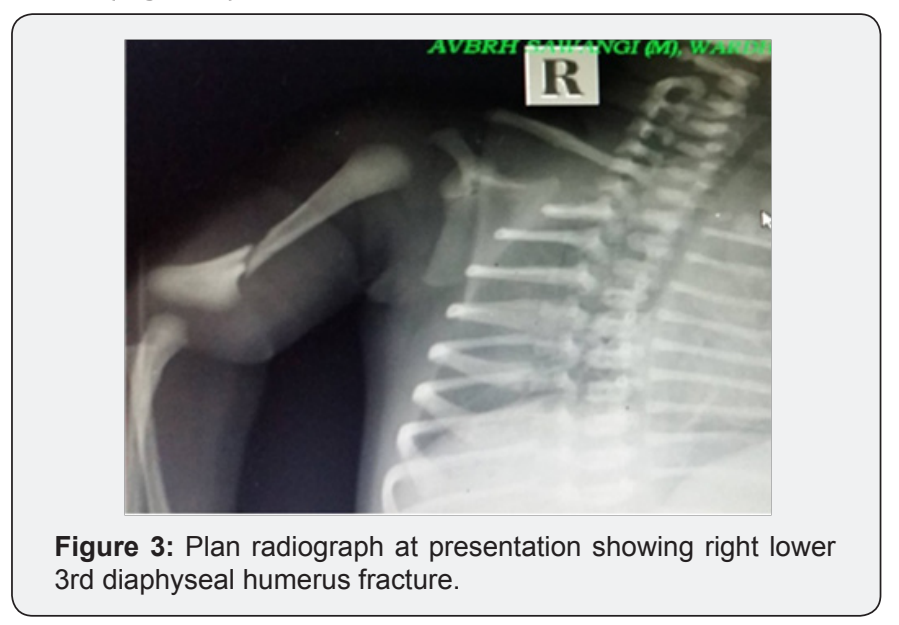

\section{Discussion}

Birth trauma is the injuries occur during the labour. They are also called as obstratics injuries. LSCS are associated with less birth injury as compared to assisted normal vaginal delivery. Various causes and risk factors are associated with this. The risk factors include obstetric maneuvers during labour, especially Caesarean sections, prolonged labor, and prematurity, macrosomia, breech presentation, shoulder dystocia and forcepassisted delivery [4,5] Although the clavicle has been reported as the commonest bone to fracture after birth trauma during LSCS other long bone fractures such as femur, humerus and monteggia fracture dislocation have also been described in literature $[6,7]$ Pathological fractures occur in infancy due to variety of causes like child abuse, osteogenesis imperfecta and rickets. Fractures secondary to demineralization from paralysis are rare during the neonatal period.

Neonates with fractures of the humerus in LSCS operative delivery is a rare occurrence. Better handling of Patients, Performing accurate and expert delivery technique followed by immediate evaluation and timely orthopedic intervention during and after delivery will prevent the fractures and help in avoiding deformities. Hence early identification of obstetric factors and improvement in obstetric care of both the mothers and babies during delivery and stoppage of traumatising manoeuvres particularly in the hands of the inexperienced would reduce the incidence and severity of this disability. Antenatal cancelling about the importance of antenatal care will play important part in the reduction of this pathology. It will be important to examine the neonates thoroughly after deliveries to detect any birth injuries and manage promptly.

\section{Conclusion}

Proper Antenatal councelling, early identification of obstetric factors for difficult labour or LSCS, stoppage of traumatising manoeuvres particularly in the hands of the inexperienced surgeon would reduce the incidence and severity of obstetric trauma. Anticipation and prompt evaluation and timely orthopedic intervention after delivery will prevent the deformities due to humerus fracture.

\section{References}

1. Edwin Dias (2012) Bilateral Humerus Fracture Following Birth Trauma. J Clin Neonatol 1(1): 44-45.

2. Alexander JM, Leveno KJ, Hauth J, Landon MB, Thom E, et al. (2006) Fetal injury associated with cesarean delivery. Obstet Gynecol 108(4): 885-890.

3. Canpolat FE, Köse A, Yurdakök M (2010) Bilateral humerus fracture in a neonate after caesarean delivery. Arch Gynecol Obstet 281(5): 967969.

4. Salonen IS, Uusitalo R (1990) Birth injuries: Incidence and predisposing factors. Z Kinderchir 45(3): 133-135.

5. Nadas S, Reinberg 0 (1992) Obstetric fractures. Eur J Pediatr Surg 2: 165-168. 
6. Bhat BV, Kumar A, Oumachigui A (1994) Bone injuries during delivery. Indian J Pediatr 61(4): 401-405.

This work is licensed under Creative Commons Attribution 4.0 License

DOI: 10.19080/OROAJ.2018.12.555835
7. Al-Habdan I (2003) Birth-related fractures of long bones. Indian J Pediatr 70(12): 959-960.

\section{Your next submission with Juniper Publishers will reach you the below assets}

- Quality Editorial service

- Swift Peer Review

- Reprints availability

- E-prints Service

- Manuscript Podcast for convenient understanding

- Global attainment for your research

- Manuscript accessibility in different formats

( Pdf, E-pub, Full Text, Audio)

- Unceasing customer service

Track the below URL for one-step submission https://juniperpublishers.com/online-submission.php 